\title{
Regras Contextuais e Morfossintáticas na Aquisição da Ortografia da Língua Portuguesa por Crianças ${ }^{1}$
}

\author{
Elisabet de Sousa Meireles \\ Jane Correa ${ }^{2}$ \\ Universidade Federal do Rio de Janeiro
}

\begin{abstract}
RESUMO - Este estudo pretendeu examinar as diferenças em complexidade apresentadas por diferentes contextos ortográficos na aquisição da ortografia da língua portuguesa. Crianças da $2^{\mathrm{a}}$ e $4^{\mathrm{a}}$ séries do ensino fundamental realizaram um ditado de palavras de baixa frequiência de exposição que incluía regras de natureza morfossintática (sufixos esa, oso e eza) e regras contextuais (usos do $r$ e $r r$ e da nasalização antes de consoantes). Observou-se uma hierarquia na aprendizagem de cada uma das regras ortográficas estudadas. Apesar da suposição de que as crianças teriam melhor desempenho nas regras contextuais do que nas morfossintáticas, os itens mais fáceis não se constituem apenas das regularidades contextuais: os sufixos esa e oso são, juntamente com regularidades contextuais, os aspectos ortográficos mais fáceis. Embora as crianças da $4^{\mathrm{a}}$ série apresentarem um maior número de acertos no ditado, as dificuldades encontradas na escrita em relação aos vários contextos ortográficos são similares para ambas as séries.
\end{abstract}

Palavras-chave: ortografia; regras de contexto; morfossintaxe; regras morfossintáticas.

\section{Contextual and Morphosyntactic Rules in Children's Acquisition of Portuguese Orthography}

\begin{abstract}
The present study intended to examine differences in complexity presented by different orthographic contexts in the acquisition of Portuguese orthography. Second- and fourth-grade children were presented with a spelling task, which included low-frequency words, based on either morphosyntactic (suffixes $e s a$, oso and $e z a$ ) or contextual (uses of $r$ and $r r$ and nasalization before consonants) rules. It was observed a clear hierarchy in the learning of the orthographic rules examined. Contrary to the idea that children would have better performance in spelling words based on contextual rules, in this study the easiest spelling items were not only the ones based on contextual rules: the use of the suffixes esa and oso is an easy orthographic rule to learn, along with some contextual rules. Although the fourth graders scored better in the task, children's difficulties with the various orthographic contexts are very similar for both grades.
\end{abstract}

Key words: spelling; contextual rules; morphosyntax; morphosyntactic rules.

A língua portuguesa é um sistema alfabético de escrita, onde os sons da fala são representados graficamente. Entretanto, para escrever corretamente a criança não poderá se basear apenas no conhecimento de regras mais básicas de correspondência grafofônica. Para escrever convencionalmente, a criança terá que se preocupar com aspectos ortográficos da língua que vão constituir uma nova fonte de dificuldades para ela. A ortografia possui diversas facetas que devem ser consideradas pela criança, já que as suas regras não são da mesma natureza e envolvem diferentes competências para sua aquisição. A criança terá, então, que realizar análises mais complexas da língua. Em alguns momentos precisará atentar para a posição de determinada letra na palavra, em outros precisará observar a classe gramatical a qual a palavra pertence, entre outras estratégias que precisará utilizar.

1 Este artigo é baseado na Dissertação de Mestrado da primeira autora, com apoio da CAPES e do CNPq, sob orientação da segunda autora, apresentada ao Programa de Pós-Graduação em Psicologia da UFRJ. Nossos agradecimentos à Secretaria Municipal de Educação do Rio de Janeiro, à escola e a seus educadores pela atenção, e, principalmente e especialmente, às crianças por sua valiosa colaboração.

2 Endereço: Universidade Federal do Rio de Janeiro, Avenida Pasteur, 250, Rio de Janeiro, RJ, Brasil 22290-240. E-mail: betmeireles@ig.com.br
Dado que a língua portuguesa não pode ser considerada absolutamente regular do ponto de vista ortográfico, Morais (1998) faz uma distinção entre as ortografias regulares e irregulares. As regulares são passíveis de compreensão das regras subjacentes permitindo uma escrita baseada em normas ortográficas, enquanto as irregulares dependeriam da memorização para escrita correta. Haveria três tipos de relações regulares: diretas, contextuais e morfológico-gramaticais.

$\mathrm{Na}$ relação regular direta, cada letra corresponde a apenas um som e vice-versa, independente de sua posição na palavra. Isto implica numa regularidade absoluta entre letra e som. Constituem este grupo as letras $<\mathrm{p}, \mathrm{b}, \mathrm{t}, \mathrm{d}, \mathrm{f}, \mathrm{v}\rangle$. Podemos citar como exemplo as palavras pato, capa e vatapá, nas quais a letra $p$ é representada pelo mesmo fonema, independente da posição que ocupe na palavra.

Para Morais (1998), as relações regulares contextuais se referem àquelas em que é possível prever a escrita correta da palavra levando-se em consideração o contexto, isto é, a posição que a letra ocupa na palavra ou a letra subseqüente. Por exemplo, a nasalização da sílaba que vier antes das letras $<$ p $>$ e $<$ b $>$ deve ser obtida pelo uso da letra $<$ m $>$, como em pomba e tampa e não através da letra $<\mathrm{n}>$, que deve ser utilizada no restante dos casos, como em canto e voando. 
Nos casos em que fosse necessário recorrer à gramática e em particular à morfologia para obter a grafia correta de uma palavra, estaríamos lidando com as relações regulares morfológico-gramaticais. Escolher entre o sufixo eza ou esa vai depender da categoria gramatical da palavra em questão: caso seja um adjetivo derivado de substantivo será escrita com a letra $<$ s $>$ (chinesa, consulesa), mas se for um substantivo derivado de adjetivo, a palavra deverá ser escrita com a letra $<\mathrm{z}>$ (realeza, pureza).

O presente estudo pretende explorar as diferenças em complexidade apresentadas por diferentes contextos ortográficos na aquisição da ortografia da língua portuguesa por crianças cursando o ensino fundamental. Objetiva descrever o conhecimento que a criança tem sobre os aspectos regulares e irregulares da ortografia da língua portuguesa, especialmente sobre as regularidades contextuais e morfossintáticas.

\section{O Conhecimento Ortográfico da Língua Portuguesa pela Criança: Evidências Empíricas}

De forma geral, os estudos sobre a aquisição da ortografia pela criança podem ser divididos em três grupos. No primeiro grupo estão os estudos que visam descrever o desempenho ortográfico através da avaliação dos tipos de erros ortográficos cometidos pelas crianças (Carraher, 1985; Nunes, 1992). $\mathrm{O}$ segundo grupo compreende os estudos que procuraram estabelecer uma relação entre competências cognitivas e a aprendizagem de aspectos ortográficos específicos (Rego \& Buarque, 1997; Sá, 1999). Por último, estão os estudos que tiveram por objetivo investigar o processo de aquisição de aspectos ortográficos específicos (Monteiro, 2000; Nunes, 1992; Rego \& Buarque, 1999).

\section{O conhecimento da ortografia através da análise dos erros ortográficos}

Os estudos que realizam uma análise qualitativa dos erros ortográficos cometidos pelas crianças ao escrever partem, em geral, da perspectiva de que tais erros não seriam cópias imperfeitas realizadas pelas crianças, mas sim tentativas válidas de grafar as palavras baseadas nas suas idéias sobre a escrita. Portanto, as produções infantis, mesmo as não convencionais, refletiriam o nível de elaboração alcançado pelas crianças sobre o conhecimento ortográfico.

Carraher (1985, ver também Nunes, 1992) investigou o desenvolvimento da escrita ortográfica em Português analisando erros cometidos por crianças brasileiras de $1^{\mathrm{a}} \mathrm{a}$ $4^{a}$ séries do ensino fundamental. Os erros das crianças envolviam aqueles relacionados à transcrição da fala (bulacha, nuveim), à supercorreção (fragio por frágil), à não utilização de regras de contexto ( rrolha, profesora ), à dificuldade na marcação da nasalização (oça no lugar de onça), à troca de letras (blástico por plástico), ao desconhecimento da origem das palavras (bulaxa por bolacha), à dificuldade na grafia de sílabas complexas, ou seja, àquelas que diferem do padrão consoante-vogal (gada por guarda).

Os erros ortográficos das palavras reais e das pseudopalavras foram classificados de forma muito semelhante. Além disto, nas palavras inventadas, apesar de ser foneticamente plausível que sufixos tais como agem e oso fossem escritos com outros grafemas (ajem, ozo), com o aumento da escolaridade as crianças tenderam a utilizar os sufixos com a grafia convencional. Exatamente por tratar-se de palavras inexistentes não se pode dizer que o correto emprego destes morfemas se baseie necessariamente em mero treino e memorização. Carraher (1985) observou ainda que, com a escolarização, há uma tendência ao decréscimo de erros de transcrição da fala, erros por desconhecimento da etimologia da palavra e erros por dificuldade na escrita de sílabas complexas. A partir da utilização de textos, houve o aparecimento de uma nova categoria de erro: a dificuldade de segmentação. A criança pode não segmentar (tipego) ou fazê-lo indevidamente (a legre). Sua ocorrência foi mais presente nos textos das crianças de $1^{\mathrm{a}}$ e $2^{\mathrm{a}}$ séries, apresentando um grande declínio a partir da $3^{\circ}$ ano.

Carraher (1985) concluiu que os erros ortográficos das crianças não são casuais, mas indicam uma compreensão da escrita, que vai se modificando conforme vão sendo adquiridos novos conhecimentos sobre a língua. Durante este processo, a criança vai estabelecendo algumas regularidades que auxiliam na utilização do sistema de escrita. A classificação dos erros ortográficos, apresentada por Carraher (1985) estabelece, do ponto de vista empírico, uma importante classificação acerca dos obstáculos encontrados pela criança na aquisição da escrita em português. No entanto, algumas das categorias descritas poderiam ser reelaboradas. A classificação da nasalização, que se refere apenas à ausência de marcação, poderia também incluir a utilização inadequada do marcador, bem como poderia ser criada uma categoria para as dificuldades relacionadas às regras ortográficas de origem morfossintática, distinguindo-as, portanto, da categoria acerca de erros pelo desconhecimento da origem das palavras, estes últimos só passíveis de acerto utilizando-se a memorização como estratégia. De qualquer forma, o estudo de Carraher (1985) contribui para uma visão mais adequada e específica acerca das dificuldades na escrita com as quais as crianças brasileiras se deparam do que a avaliação comumente realizada que se baseia apenas na reprodução correta da grafia convencional da palavra.

\section{Competências cognitivas e a aprendizagem da ortografia}

Rego e Buarque (1997) realizaram estudo longitudinal para examinar a influência da consciência fonológica - capacidade de reflexão e manipulação intencional das unidades sonoras das palavras (Cardoso-Martins, 1995; Gombert, 1992; Goswami \& Bryant, 1990; Leal \& Roazzi, 2000) - e da consciência sintático-semântica - habilidade de refletir e manipular intencionalmente a estrutura gramatical e o significado das sentenças (Rego, 1995) - na aquisição de regras ortográficas da língua portuguesa. Foram utilizadas palavras e pseudopalavras que continham regularidades contextuais (por ex. uso dos dígrafos rr e qu) e regularidades morfossintáticas (por ex. a representação de /ow/ em verbos e substantivos). As crianças foram avaliadas quanto à consciência sintática e à consciência fonológica no início da $1^{\mathrm{a}}$ série e quanto à competência ortográfica, no final da $1^{\mathrm{a}}$ série e no final da $2^{\mathrm{a}}$ série.

Os resultados indicaram relação entre consciência sintática e a aquisição de regras que implicam análise gramatical. 
O conhecimento sobre os morfemas indicadores do tempo passado, por exemplo, seria facilitado pela consciência sintática e não dependeria nem da capacidade de leitura nem da compreensão de textos. Um outro dado relevante se refere à não importância da consciência sintática como determinante na aquisição de regras de contexto grafofônico, que seriam influenciadas pela consciência fonológica. Desta forma, consciência fonológica e consciência sintática estariam relacionadas com a aprendizagem de regras ortográficas específicas. A aquisição de regras de contexto seria facilitada pelo desenvolvimento da consciência fonológica, enquanto que aspectos ortográficos ligados à morfologia e à sintaxe estariam relacionados à consciência sintática.

Sá (1999), através de estudo transversal, procurou examinar se a consciência morfossintática, capacidade de refletir e manejo consciente das estruturas morfológica e sintática da língua (Nunes, Bryant \& Bindman, 1997), estaria relacionada à aquisição da ortografia. Participaram deste estudo 60 crianças brasileiras de $2^{\mathrm{a}}$ e $3^{\mathrm{a}}$ séries do ensino fundamental de uma escola particular. Foram realizadas tarefas de avaliação da consciência morfossintática e do desempenho ortográfico.

Para medir a competência ortográfica das crianças foram utilizadas tarefas de ditado de palavras e escrita espontânea. O ditado de palavras era constituído por verbos de $2^{\mathrm{a}}$ e $3^{\mathrm{a}}$ conjugação do pretérito perfeito do modo indicativo (escreveu, partiu) e do pretérito imperfeito do modo subjuntivo (comesse, descobrisse), palavras de outras categorias gramaticais, cuja terminação apresenta similaridade fonética, mas não gráfica, com a dos verbos já indicados (agradável, fértil, merece, maluquice) e palavras inventadas para controlar o efeito da memorização (desumiu, aflitisse, sujável, atorece). O objetivo era investigar a utilização das terminações $e u, i u$, isse e esse, cuja escrita correta depende de considerações morfossintáticas. Os resultados indicam que há uma relação significativa entre a consciência morfossintática e o desempenho ortográfico apresentado pelas crianças. Quanto maior o nível de consciência morfossintática, maior o número de acertos nas palavras investigadas.

Os resultados obtidos nos estudos Rego e Buarque (1997) e Sá (1999) sugerem, portanto, a existência de uma relação entre competências metalingüísticas e o desenvolvimento da escrita em Português, sendo que diferentes competências facilitariam a aquisição de diferentes aspectos ortográficos. A consciência morfossintática parece influenciar a escrita de palavras cuja grafia correta implica na compreensão de aspectos morfossintáticos da língua, enquanto que a consciência fonológica estaria relacionada à aprendizagem das regularidades contextuais.

\section{O desenvolvimento da escrita em contextos ortográficos específicos}

Os estudos desta seção voltam-se para a investigação da transição de uma fase alfabética de escrita para uma ortográfica, em que a criança passaria a lidar com aspectos ortográficos específicos da língua portuguesa que iriam além das correspondências básicas entre letra e som. Nunes (1992) procurou examinar a trajetória de erros ortográficos relacionados às regras contextuais, para verificar se estes são corrigidos simultaneamente pelas crianças ou em momentos diferentes da aquisição da leitura e da escrita. Para isto, regras cujo ensino não ocorre de forma explícita na escola foram investigadas através do uso de palavras inventadas que apresentavam apenas uma pronúncia ou grafia possíveis, não sendo derivadas de palavras primitivas conhecidas.

Nunes (1992) comparou a aquisição de regras de contexto semelhantes por crianças de $1^{\mathrm{a}}$ a $4^{\mathrm{a}}$ série do ensino fundamental. Nas sílabas átonas em final de palavras, apesar da pronúncia ser $/ \mathrm{i} /$ ou $/ \mathrm{u} /$, deve-se usar as letras $\langle\mathrm{e}\rangle$ ou $\langle 0\rangle$ respectivamente, para grafar corretamente a palavra. $\mathrm{O}$ objetivo, então, foi o de verificar se as crianças aprenderiam a colocar as letras $<0\rangle$ e $<$ e $\rangle$ concomitantemente ou se uma regra precederia a outra, apesar de serem tão parecidas. A diferença existente entre os processos de leitura e escrita foi também examinada.

Os resultados indicam que a aquisição de regras ortográficas de mesma natureza não ocorre simultaneamente pelas crianças. A representação do /u/ átono no final de palavras é aprendida mais rapidamente do que a representação do /i/, tanto na leitura quanto na escrita. Observou-se que, na leitura, a utilização das regras contextuais foi maior do que na escrita. A diferença encontrada entre a leitura e a escrita provavelmente estaria refletindo as características particulares de cada um destes processos. Na leitura, as pistas semânticas facilitariam na decodificação do que está escrito, enquanto que na escrita não haveria este tipo de artifício.

Nunes (1992) conclui que as regras ortográficas não são adquiridas concomitantemente, pois mesmo aquelas que se apresentam gramaticalmente similares não são aprendidas pelas crianças ao mesmo tempo. Portanto, cada contexto ortográfico seria adquirido sem estar subordinado a uma aprendizagem conjunta para regras de natureza semelhante.

Rego e Buarque (1999) investigaram as dificuldades que as crianças das quatro séries iniciais do ensino fundamental encontram para escrever regras ortográficas específicas. Foram abordadas regras referentes à utilização do $r$ e $r r \mathrm{e}$ o contraste entre as grafias das terminações $o u$ (presente na $3^{\text {a }}$ pessoa do singular do pretérito perfeito de verbos de $1^{\text {a }}$ conjugação), e or (presente em substantivos), além da comparação entre o iu (terminação da $3^{\text {a }}$ pessoa do singular do pretérito perfeito de verbos de terceira conjugação), io e $i l$ (terminações de substantivos e adjetivos).

Com relação ao uso do $r$ e $r r$, foram examinados os contextos $/ \mathrm{R} /$ intervocálicos, $/ \mathrm{R} /$ inicial, $/ \mathrm{r} /$ intervocálico e $/ R /$ entre consoante e vogal (que inclui o/R/ depois de vogal nasal). O desempenho apresentado pelas crianças nestes contextos foi dividido em seis etapas. No início, a criança não faz uso do dígrafo, utilizando apenas um $r$ para representar todos os contextos (rajão, coredor, omra). Em seguida, a criança passa a utilizar o dígrafo apenas no meio da palavra, sem fazer, no entanto, discriminações sonoras (ragão, corredor, onrra). Posteriormente, a criança discrimina o uso do $r$ ou $r r$ de acordo com o som apresentado (rrajão, corredo, garinpão, onrra). De outras vezes, o contexto/R/intervocálico é representado com apenas um $r$ e o contexto /R/ entre consoante e vogal é representado de forma isolada pelo dígrafo ( guitarista). Após isto, a criança grafa corretamente os contextos, com exceção do entre consoante e vogal, que é marcado pelo uso uniforme do dígrafo (raquetão, garimpão, genrro). 
Finalmente todos os contextos são representados de acordo com a norma ortográfica (guitarrista, garimpão, genro).

O outro aspecto observado foi a diferenciação entre as grafias ou e or (na fala destas crianças, a pronúncia dos verbos terminados em ou é igual a dos substantivos terminados em or). Para verificar a aquisição destes aspectos morfossintáticos, a produção escrita das crianças foi novamente categorizada de acordo com o desempenho apresentado. Inicialmente aparecia a utilização da letra $<0>$ para representar a terminação do verbo e do substantivo (izagero, jogado) seguido do uso indiscriminado do ou e or. Posteriormente, a criança já distinguiria as palavras gramaticalmente, utilizando ou e $o l$ para marcar a terminação verbal e $o$ e or para o substantivo (zangol, calor). Depois, a criança escreveria corretamente uma das categorias gramaticais, cometendo erros na outra (jogou, zombado ou jogool, sombador). Finalmente foi observada a utilização correta das terminações nos verbos e nos substantivos (sangou, jogador).

Quanto à aquisição do $i u$, io e $i l$ foram obtidas as seguintes categorias de desempenho. Inicialmente a criança escreveria fazendo uma transcrição da fala e, portanto, utilizando $i u$ para grafar todas as classes gramaticais, indistintamente (ouviu, paviu). Depois, a criança utilizaria indiscriminadamente as representações investigadas ou uma das representações é eleita para representar a terminação de todas as categorias gramaticais. Posteriormente, a representação iu é utilizada apenas em verbos e as outras representações ainda são utilizadas indiscriminadamente (partiu, presitio, bario). Finalmente, a criança escreve corretamente as terminações dos verbos, adjetivos e substantivos (navio, partiu).

Monteiro (2000) procurou averiguar como ocorre a aprendizagem de regras contextuais na leitura e na escrita por crianças de ensino fundamental, abrangendo a classe de alfabetização até a $4^{\mathrm{a}}$ série. Mais especificamente foi analisada a regra de contexto de uso do $<s>$ entre vogais, tendo sido feita a inclusão do $<s>$ e $<z>$ em início de palavras para verificar se as crianças fariam generalizações inadequadas da regra para estes contextos. Quando entre vogais, o som /s/ deve ser representado com o dígrafo ss, enquanto que para marcar o som /z/ apenas um $<s>$ deve ser utilizado. Os erros cometidos pelas crianças foram analisados em função do padrão de comportamento adotado ao grafar ou ler as palavras das tarefas, procurando determinar em que período de compreensão da regra a criança estaria. A partir disto, foram montadas categorias relativas ao desempenho apresentado pelas crianças, que sugerem a existência de fases na aprendizagem da regra de contexto de uso do $\langle s\rangle$ entre vogais. Inicialmente, a criança representa o som /s/ com a letra $\langle s>$ e o som /z/ com a letra $\langle z>$. Exemplos: vazo, sono, asado. Posteriormente haveria duas possibilidades de escrita das crianças: a) a criança percebe que a letra $<s>$ pode representar mais de um som e faz generalizações para todos os contextos. Exemplos: sacola, sona, dise; e b) a criança passa a utilizar grafias como $s, s s, c ̧, c$ e $z$ para representar os sons /s/ e /z/, algumas vezes empregando corretamente a representação e em outros fazendo generalizações inadequadas. Exemplos: pezado, zebra, nosso. Finalmente, a criança emprega corretamente as letras $<\mathrm{s}>$ e $<\mathrm{z}>$ ou comete apenas erros eventuais. Exemplos: mesa, zelador, dise.
Monteiro (2000) verificou grande semelhança nas estratégias utilizadas pelas crianças na leitura e na escrita. A leitura se destacou pela maior facilidade que a tarefa impõe a criança. As etapas de aquisição do $s$ entre vogais indicam que as crianças vão estabelecendo regularidades para escrever palavras e, pouco a pouco, vão reconstruindo as hipóteses elaboradas de acordo com as novas informações que lhes são apresentadas.

Os estudos de Monteiro (2000), Nunes (1992) e Rego e Buarque (1999) apresentam um percurso comum no desenvolvimento de aspectos ortográficos. Inicialmente a criança escreve as palavras foneticamente, ou seja, a pronúncia da palavra é representada integralmente na escrita de acordo com as correspondências grafofônicas regulares aprendidas pelas crianças. Conforme a criança vai tendo contato com novas possibilidades de se grafar determinado contexto ortográfico, vai havendo uma reestruturação das hipóteses anteriores a partir das novas informações. Isto gera uma fase de generalizações indevidas, pois a criança ainda não sabe onde deve empregar a nova grafia, podendo inclusive cometer erros em palavras que antes escrevia corretamente. Gradualmente, a criança vai compreendendo as restrições implicadas naquele determinado padrão ortográfico. Por fim, a criança começa a utilizar adequadamente o contexto ortográfico, o que indica uma aprendizagem efetiva, com a aquisição de um conhecimento mais elaborado.

Nos estudos acima mencionados, pode-se também observar diferenças em termos da complexidade apresentada pelos contextos ortográficos. Alguns contextos ortográficos parecem ser adquiridos mais facilmente do que outros. Além disto, o processo de desenvolvimento apresenta variações de acordo com as particularidades e especificidades de cada padrão ortográfico investigado. No entanto, isto não invalida um modelo mais geral de desenvolvimento, pois as características de cada contexto parecem gerar diferenças em relação à produção, mas não ao processo.

\section{Questões e Hipóteses}

O objetivo da presente pesquisa é o de examinar o conhecimento ortográfico da criança com níveis diferentes de escolaridade, explorando as diferenças em complexidade entre as regularidades contextuais e morfossintáticas da língua portuguesa. Em termos lingüísticos, as regras ortográficas não decorrem apenas do nível fonológico da língua, sendo algumas determinadas em nível morfossintático (Morais, 1999). Desta forma, as regras cuja compreensão requeira conhecimentos além daqueles decorrentes do domínio do princípio alfabético pela criança e das correspondências grafofônicas pelas crianças seriam de aquisição posterior.

Neste caso, poder-se-ia hipotetizar que as regras de natureza morfossintáticas, quer porque, em termos lingüísticos, referem-se a níveis de análise além do fonológico, quer, em termos cognitivos, por estarem relacionados ao desenvolvimento da consciência morfossintática, seriam de natureza mais complexas para as crianças do que regras contextuais, cujo aprendizado seria influenciado pelo desenvolvimento da consciência fonológica (Rego \& Buarque, 1997).

Examinamos, ainda, de acordo com Nunes (1992), se regras que se referem a um mesmo nível de análise lingüística, 
no caso do presente estudo, regras de contexto (uso do $r$ e $r r$ e nasalização diante de consoantes), apresentariam níveis diferenciados de dificuldade relativa para as crianças.

\section{Método}

\section{Participantes}

Participaram deste estudo 52 crianças cursando o ensino fundamental em uma escola pública na cidade do Rio de Janeiro. A escola atende em sua maioria crianças de classe média e média baixa. Foram 24 crianças de $2^{\mathrm{a}}$ série, com média de idade de 9 anos (idade mínima: 8 anos e 4 meses; idade máxima: 9 anos e 4 meses, sendo nove meninas e 15 meninos) e 28 crianças de $4^{\text {a }}$ série, com média de idade de 11 anos e 1 mês (idade mínima: 10 anos e 3 meses; idade máxima: 11 anos e 11 meses; 14 meninas e 15 meninos). $\mathrm{O}$ trabalho foi iniciado com a $2^{\mathrm{a}}$ série pois, nesta série, as crianças já estariam alfabetizadas e iniciando uma fase ortográfica em sua escrita. $\mathrm{O}$ intervalo de um ano dado entre as séries baseia-se em estudo realizado por Monteiro (1995), no qual observa-se que apenas com uma intermitência superior a um ano poder-se-ia verificar diferenças na aquisição da ortografia.

\section{Procedimentos}

Foi realizado um ditado de palavras no qual os alunos receberam um protocolo contendo 49 sentenças com lacunas que foram completadas com as palavras ditadas pela professora. Os alunos foram avisados de que fariam um ditado, no qual deveriam prestar atenção na frase para completar a folha de resposta com a palavra que estaria faltando (Vou pintar a casa com amarela. tinta).

As sentenças foram lidas integralmente e, em seguida, a palavra que estava faltando foi repetida isoladamente para que a criança pudesse escrevê-la. As palavras foram repetidas por até três vezes. Os professores foram instruídos a ler as frases e as palavras de forma corrente, sem artificialização da pronúncia. Foram utilizadas as mesmas frases para ambas as séries investigadas. Devido à quantidade de palavras, o ditado foi dividido e realizado em duas sessões, que tiveram duração média de 30 minutos.

Foram estudadas as regularidades morfossintáticas presentes no sufixo eza, que é empregado na formação de nomes abstratos derivados de adjetivos, como é o caso das palavras delicadeza e moleza; no sufixo esa relacionado a nomes que indicam profissão, título ou posição social e o local de origem do sujeito, como nas palavras camponesa e japonesa; e no sufixo oso referente a adjetivos comofamoso e populoso. No caso das regras de contexto trabalhamos com o emprego do $r$ e $r r$ e a nasalização. Examinamos o emprego do $r$ e $r r$ nos seguintes contextos: /R/ intervocálico (beterraba), /r/ intervocálico (maratona), /R/ inicial (rotina), /R/ precedido de vogal nasal (genro) e /R/ precedido de consoante (desrespeito). Avaliamos a nasalização diante de p e b (empada e pomba) e a nasalização diante das demais consoantes (lenda).

O ditado foi composto por palavras com baixa freqüência de ocorrência em todas as séries investigadas (Pinheiro, 1996), minimizando assim a possibilidade de escrita base- ada na exposição contínua a sua grafia ou na memorização. Foram evitadas palavras que apresentavam mais de um tipo de restrição ortográfica, sendo que isto não foi possível em alguns poucos casos, dada a limitação imposta pelo uso de palavras infrequientes. Para a maioria dos contextos estudados foram selecionadas cinco palavras. Nos casos de nasalização, foram escolhidas 12 palavras, sendo três delas para nasalização antes de $p$, três para antes de $b$ e seis diante das demais consoantes. A listagem de palavras infrequientes para todas as séries do ensino fundamental possuía um número restrito de palavras com a representação/R/ precedido de consoante. Por isto, só foi possível a inclusão de duas palavras deste contexto no ditado de palavras.

\section{Resultados}

Foram computados apenas os acertos das crianças nos contextos específicos referentes às regras de contexto $(/ \mathrm{R} /$ intervocálico, /r/ intervocálico, /R/ inicial, /R/ precedido de vogal nasal, /R/ precedido de consoante, nasalização diante de $p$ e $b$ e nasalização diante das demais consoantes) e às regras morfossintáticas (sufixos oso, eza e esa). Ao escrever, por exemplo, farova ao invés de farofa, apesar da palavra conter um erro de ortografia, a criança receberá pontuação pelo acerto, pois, neste momento, apenas o contexto /r/ intervocálico está sendo investigado. Foi calculada, então, a proporção média de acertos das crianças de $2^{\mathrm{a}}$ e $4^{\mathrm{a}}$ séries para os contextos críticos investigados conforme mostrado na Tabela 1.

Quanto ao uso do $r$ e $r r$, observou-se que nos contextos /R/ inicial e /r/ intervocálico, as crianças de $2^{\mathrm{a}}$ e $4^{\mathrm{a}}$ série apresentaram elevado número de acertos, indicando que, a

Tabela 1. Proporção média de acertos para os diversos contextos ortográficos por série

\begin{tabular}{|c|c|c|}
\hline \multirow{2}{*}{ Contextos } & \multicolumn{2}{|c|}{ Série } \\
\hline & 2 & 4 \\
\hline \multirow[t]{2}{*}{ /R/ depois de consoante } & 0,44 & 0,64 \\
\hline & $(0,43)$ & $(0,43)$ \\
\hline \multirow[t]{2}{*}{ /R/ depois de vogal nasal } & 0,51 & 0,64 \\
\hline & $(0,35)$ & $(0,38)$ \\
\hline \multirow[t]{2}{*}{ /R/ intervocálico } & 0,78 & 0,89 \\
\hline & $(0,31)$ & $(0,25)$ \\
\hline \multirow[t]{2}{*}{ /r/ intervocálico } & 0,94 & 1,00 \\
\hline & $(0,12)$ & $(0)$ \\
\hline \multirow[t]{2}{*}{$/ \mathrm{R} /$ inicial } & 0,99 & 1,00 \\
\hline & $(0,04)$ & (0) \\
\hline \multirow[t]{2}{*}{ Nasalização com m } & 0,69 & 0,97 \\
\hline & $(0,41)$ & $(0,07)$ \\
\hline \multirow[t]{2}{*}{ Nasalização com n } & 0,97 & 0,99 \\
\hline & $(0,07)$ & $(0,04)$ \\
\hline \multirow[t]{2}{*}{ Sufixo $e z a$} & 0,30 & 0,66 \\
\hline & $(0,34)$ & $(0,32)$ \\
\hline \multirow[t]{2}{*}{ Sufixo esa } & 0,72 & 0,87 \\
\hline & $(0,27)$ & $(0,20)$ \\
\hline \multirow[t]{2}{*}{ Sufixo oso } & 0,88 & 0,99 \\
\hline & $(0,24)$ & $(0,04)$ \\
\hline
\end{tabular}

Nota: Valores entre parênteses indicam o desvio padrão. 
partir da $2^{\mathrm{a}}$ série, as crianças já dominam tais representações, razão pela qual estes contextos foram excluídos da Análise de Variância. O desempenho das crianças mostrou-se influenciado pela escolaridade, $F(1,50)=5,87, p=0,019$. As crianças de $4^{a}$ série têm melhor domínio dos usos do $r$ e do $r r$. Algumas destas representações, no entanto, mostraram-se mais fáceis para as crianças do que outras, $F(2,100)=11,07$, $p<0,001$. Seria possível, de acordo com os resultados do post-hoc teste (Newman-Keuls), dividir os contextos do uso do $r$ e $r r$ em dois grupos: um contendo a representação /R/ intervocálico; e o outro, as representações /R/ depois de consoante e /R/ depois de vogal nasal, estas de maior dificuldade para as crianças.

Quanto ao domínio da nasalização, a escolaridade também influenciou o desempenho das crianças, $F(1,50)=12,40$, $p<0,01$. De maneira geral, o uso do $m$ como marcador de nasalização foi mais difícil para as crianças do que quando o marcador empregado foi o $n, F(1,50)=15,64, p<0,01$. Por outro lado, os resultados da Análise de Variância mostraram que a interação entre contexto crítico e escolaridade foi significativa, $F(1,50)=12,09, p<0,01$. Post-hoc teste (Newman-Keuls) indicou que tal influência estaria relacionada apenas ao uso do $m$ antes de $p$ e $b$. Este contexto seria de domínio apenas das crianças com maior escolaridade. Por outro lado, desde a $2^{\text {a }}$ série, as crianças usariam com sucesso o $n$ como marcador de nasalização.

No que se refere ao uso das regras morfossintáticas, viuse, novamente, que, de maneira geral, o melhor desempenho no ditado foi das crianças da $4^{\mathrm{a}}$ série, $F(1,50)=38,82, p<$ 0,01 . Existiu uma hierarquia em termos de dificuldade relativa entre os sufixos: o sufixo oso sendo o mais fácil e o $e z a$ o de maior dificuldade, $F(2,100)=38,96, p<0,01$. A interação entre contexto ortográfico e escolaridade foi significativa, $F(2,100)=3,07, p=0,05$. A aplicação do post-hoc teste (Newman-Keuls) indicou que não houve diferença entre as séries quando do uso do sufixo oso, e que a $4^{\mathrm{a}}$ série não experimentou maiores dificuldades quer no emprego do sufixo oso, quer no emprego do sufixo esa.

A fim de analisar as diferenças e similaridades entre os contextos ortográficos foi realizada uma Análise de Agrupamento Hierárquica com os dados obtidos nas tarefas de avaliação do desempenho ortográfico. A Análise de Agrupamento Hierárquica tenta identificar grupos relativamente semelhantes de acordo com características selecionadas, em nosso caso, o desempenho das crianças no ditado de palavras. A Tabela 2 apresenta o esquema de aglomeração com o registro dos coeficientes de aglomeração para a constituição dos diversos grupos dentro das regras ortográficas estudadas segundo a escolaridade das crianças.

As Figuras 1 e 2 mostram os dendrogramas, ou seja, a representação visual de cada estágio de aglomeração, para os diferentes contextos ortográficos em cada série. A análise dos dendrogramas aliada à inspeção dos coeficientes de aglomeração mostram que o melhor agrupamento que se pode obter dos dados é o de três grupos: um reunindo as regras de nasalização diante de consoantes, os sufixos oso e esa, o/R/ inicial, /R/ intervocálico e /r/ intervocálico; o segundo com as regras de contexto /R/ depois de vogal nasal e /R/ depois de consoante; e, um último, contendo o sufixo eza.
Tabela 2. Análise de agrupamento hierárquico das regras ortográficas por série

\begin{tabular}{lcrc} 
Estágio & Agrupamento 1 & Agrupamento 2 & Coeficientes \\
\hline \multicolumn{3}{c}{$\mathbf{2}^{\text {a }}$ Série } \\
1 & 3 & 10 & 0,18 \\
2 & 2 & 3 & 0,53 \\
3 & 2 & 6 & 1,50 \\
4 & 1 & 9 & 2,20 \\
5 & 2 & 8 & 2,83 \\
6 & 4 & 5 & 3,83 \\
7 & 1 & 2 & 4,26 \\
8 & 4 & 7 & 7,01 \\
9 & 1 & 4 & 10,44 \\
\hline & & & \\
1 & 12 & 13 & 0,00 \\
2 & 16 & 20 & 0,03 \\
3 & 12 & 16 & 0,05 \\
4 & 12 & 19 & 0,20 \\
5 & 14 & 15 & 1,46 \\
6 & 12 & 18 & 1,52 \\
7 & 11 & 12 & 2,08 \\
8 & 11 & 17 & 5,59 \\
9 & 11 & 14 & 7,99 \\
\hline
\end{tabular}

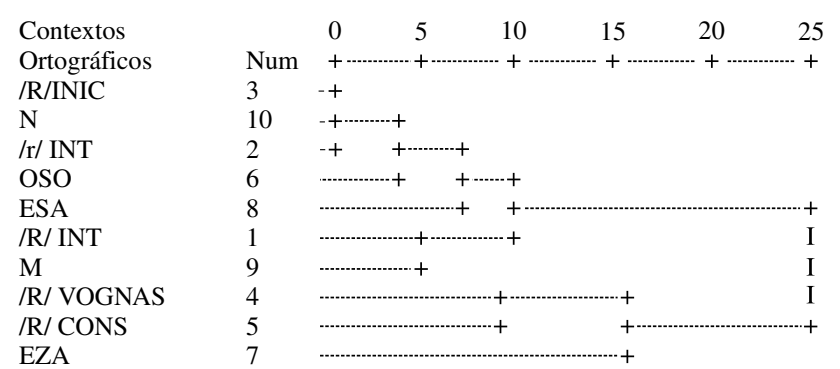

Figura 1. Dendrograma da análise de agrupamento hierárquico das regras ortográficas na $2^{\mathrm{a}}$ série.

Contextos
Ortográficos
/r/INT
/R/INIC
OSO
$\mathrm{N}$
$\mathrm{M}$
ESA
/R/INT
EZA
/R/ VOGNAS
/R/ CONS

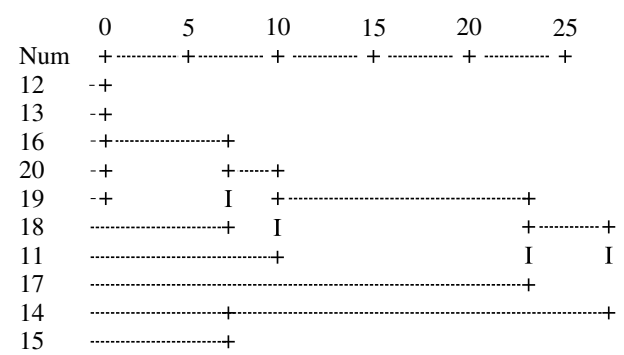

Figura 2. Dendrograma da análise de agrupamento hierárquico das regras ortográficas na $4^{\mathrm{a}}$ série.

A análise dos agrupamentos sugere que os contextos ortográficos problemáticos são os mesmos para a $2^{\mathrm{a}}$ e a $4^{\mathrm{a}}$ séries, ou seja, os contextos que são difíceis para uma série também são difíceis para a outra. A diferença entre as duas séries estaria na quantidade de erros ortográficos cometidos, sendo que as crianças da série mais avançada apresentariam um número mais reduzido de erros do que as de série mais 
baixa. Também pode-se observar que nos três grupos que se formaram, dois se constituem exatamente pelas principais fontes de dificuldade encontradas pelas crianças $-/ R /$ depois de consoante, /R/ depois de vogal nasal e sufixo eza - e o terceiro conteria a maior parte das regularidades contextuais enfocadas neste estudo. Curiosamente, nota-se que os sufixos esa e oso, que poderiam ser considerados como contextos difíceis pela regra morfossintática subjacente, encontram-se no grupo mais fácil para as crianças, junto com as regularidades contextuais. Tais resultados parecem indicar que seja pouco provável que as crianças estejam fazendo a escolha da letra com base na categoria gramatical das palavras para grafar os sufixos $e s a$ e $o s o$. Na verdade, a opção pela letra $s$ para grafar estes sufixos parece estar relacionada a uma regra de contexto na qual a letra $s$ entre vogais representa o som /z/.

\section{Discussão e Considerações Finais}

Pretendeu-se, no presente estudo, examinar as diferenças em complexidade apresentadas por diferentes contextos ortográficos na aquisição da ortografia da língua portuguesa. Crianças cursando a $2^{\mathrm{a}}$ e $4^{\mathrm{a}}$ séries do ensino fundamental realizaram um ditado de palavras de baixa freqüência que incluía regras de natureza morfossintática, uso dos sufixos esa, oso e eza, e regras contextuais, relativas aos usos do $r$ e $r r$ e da nasalização antes de consoantes.

Os resultados indicam que certos contextos ortográficos são mais fáceis para as crianças do que outros. Entretanto, apesar da suposição de que as crianças teriam melhor desempenho nas regras contextuais do que nas morfossintáticas, os contextos mais fáceis não se constituem apenas das regularidades contextuais. Os sufixos esa e oso fazem parte do grupo no qual as crianças apresentaram boa performance, provavelmente pela utilização "emprestada" de uma regra contextual. As representações /R/ depois de consoante, /R/ depois de vogal nasal e o sufixo eza são os contextos nos quais as crianças encontraram maior dificuldade.

Os resultados encontrados apontam a existência de uma hierarquia na aprendizagem dentro das regras ortográficas estudadas. Certos contextos ortográficos seriam utilizados de forma adequada mais rapidamente do que outros. Esta hierarquia interna aponta para uma aprendizagem que se daria inicialmente de forma parcial. Apenas uma parte das representações relacionadas à regra ortográfica seria empregada corretamente pelas crianças em sua produção escrita, isto é, a criança inicialmente consideraria somente alguns aspectos referentes a estas regras. A medida em que vai aumentando a idade e a escolaridade, a criança passa a usar de forma mais consistente a regra ortográfica. Estudos como o de Monteiro (2000) e Rego e Buarque (1999) confirmam a existência de um percurso para a aquisição da ortografia, que apresenta variações de acordo com o padrão ortográfico em questão.

Inicialmente as crianças fariam uma escrita fonética das palavras. Depois, perceberiam que apenas as correspondências entre letra e som mais básicas não são suficientes para gerar a escrita correta. Este segundo momento envolveria a incorporação da nova possibilidade de se grafar a palavra, mas ainda não haveria uma compreensão clara acerca dos contextos em que esta deveria ser aplicada. Isto geraria um uso indiscriminado da nova aquisição, com generalizações para contextos inapropriados. Posteriormente, a criança passaria a utilizar a regra ortográfica adequadamente.

Tomando como base as fases indicadas por Rego e Buarque (1999) pode-se organizar, por exemplo, a aquisição do $r$ e $r r$ em etapas. As crianças utilizariam inicialmente apenas uma letra $r$ para marcar tanto o som /R/ quanto /r/. Posteriormente, a criança se daria conta da utilização dos dois $r r$, mas adotaria a nova grafia de forma indiscriminada, não considerando ainda nem o som nem a posição que a letra ocupa na palavra. Seria possível, por exemplo, verificar na escrita da criança a representação do som /r/ com dois $r r$. Em uma terceira etapa, a criança já utilizaria a regra ortográfica de forma adequada, se baseando no som para escrever a palavra - o som forte seria representado com dois $r r$ e o som fraco com um $r$ só - e também na posição da letra na palavra - não se usa dois $r r$ no início da palavra, apenas no meio. Por último, as crianças compreenderiam que no meio da palavra, mesmo que o som seja /R/, só é possível utilizar os dois $r r$ quando entre vogais.

As crianças deste estudo, de forma geral, estariam alcançando a terceira fase do desenvolvimento das regras contextuais de uso do $r$ e $r r$. Já haveria uma escrita consistente das representações / $R /$ inicial e /r/ intervocálico, que seriam as primeiras a serem aprendidas pelas crianças. A representação /R/ intervocálico estaria ainda em um nível intermediário de aquisição, especialmente para as crianças de $2^{\mathrm{a}}$ série. Já o /R/ depois de consoante e o /R/ depois de vogal nasal, que só serão devidamente incorporados posteriormente, destacaramse pelo nível de dificuldade que colocam para as crianças, inclusive as de $4^{\mathrm{a}}$ série.

Aplicando este modelo também à nasalização diante de consoantes e aos sufixos esa, oso e eza, considerando-se as particularidades e especificidades de cada regra, pode-se chegar a um possível percurso de desenvolvimento para cada uma destas regras em questão, tendo como base os resultados encontrados no presente estudo.

Na nasalização diante de consoantes, as crianças inicialmente tenderiam a omitir o marcador de nasalização. Posteriormente fariam uso dos marcadores indiscriminadamente, o que geraria a escrita, por exemplo, de tãpa ao invés de tampa. Após esta fase, notariam que a nasalização em final de sílaba, diante de consoantes, é feita pelo uso do $m$ ou $n$. O emprego do $n$ diante de consoantes já estaria estabelecido na grafia das crianças, enquanto que o $m$ só seria completamente adquirido em um estágio posterior.

Neste estudo, as crianças já teriam adotado o $n$ como marcador de nasalização com sucesso para ambas as séries. Já o emprego correto do $m$, diante de $p$ e $b$, está consolidado apenas na série mais avançada. Portanto, as crianças de $2^{\mathrm{a}}$ série estariam na terceira fase de desenvolvimento da escrita da nasalização diante de consoantes, enquanto que a aquisição desta regra de contexto já estaria completa na $4^{\mathrm{a}}$ série.

Quanto às regras morfossintáticas investigadas neste estudo, a fase fonética implicaria na escrita dos sufixos oso, esa e eza com o grafema $z$, que é a letra que as crianças inicialmente mais associam ao som /z/. Na segunda fase, a criança percebe que o $s$ também é uma letra possível para grafar este som e passa a fazer um uso indiscriminado dos grafemas $s$ e $z$. Isto nos remete ao estudo realizado por Monteiro (2000) sobre a aprendizagem da regra contextual referente ao uso 
da letra $s$ entre vogais. Algumas vezes, a criança também adota outros grafemas para grafar o /z/, como o ss, ç e $c$. Estes não são empregados por apresentarem o som /z/, mas, provavelmente, por concorrerem com a letra s em outros contextos para marcar o som /s/. Em seguida, a utilização do $s$ se torna mais consistente e não há mais a utilização das grafias alternativas. A adoção da letra $s$ não parece refletir um conhecimento gramatical, mas sim a aplicação de uma regra contextual, na qual o $s$ teria valor sonoro /z/ quando se encontra entre vogais. O uso do $s$ ocorreria, deste modo, tanto nos adjetivos quanto nos substantivos. Finalmente, a criança faz a utilização adequada das letras $s$ e $z$ nos sufixos oso, esa e eza, possivelmente por um conhecimento, mesmo que implícito, da classe gramatical das palavras.

As crianças deste estudo estariam, de forma geral, utilizando os sufixos esa e oso apropriadamente, principalmente as de $4^{\mathrm{a}}$ série, provavelmente pela adoção da letra $s$ como preferencial para marcar o som /z/. Análise do agrupamento hierárquico estabelece uma proximidade dos sufixos esa e oso com regularidades contextuais mais fáceis para as crianças, sugerindo que a escrita destes sufixos pode estar sendo determinada pela regra contextual referente a utilização da letra $s$ entre vogais. $\mathrm{Na}$ escrita do sufixo eza, as crianças apresentaram desempenho mais baixo, sendo, portanto, o contexto problemático na aprendizagem destas regularidades morfossintáticas. Isto indica que a criança ou não utiliza ou não possui um conhecimento gramatical necessário para facilitar a escrita destas palavras.

Assim, nem sempre é legítimo inferir, de imediato, a estratégia cognitiva utilizada pela criança no emprego de determinada regra ortográfica baseada apenas nas características lingüísticas da regra. Conforme ilustrado pelo emprego dos sufixos oso, esa e eza, o sucesso das crianças ao grafarem os sufixos esa e oso estaria provavelmente relacionado à possibilidade de poderem, para estas grafias, empregar competências já adquiridas para lidarem com as regras de natureza contextual do que ao desenvolvimento de habilidades de natureza morfossintática, como seria o esperado, uma vez considerados somente os aspectos lingüísticos envolvidos.

Com base nos estudos sobre os níveis de desenvolvimento da ortografia, fica evidente que o desempenho ortográfico deve ser avaliado a partir da consideração de todos os contextos implicados na aquisição da regra. Desta forma, podese determinar em que nível se encontra a aprendizagem de determinado aspecto ortográfico. Ao investigar a aquisição do uso do $r$ e $r r$, por exemplo, não é suficiente examinar apenas dois dos cinco contextos em que se deve empregar esta regra, pois isto resultaria numa visão parcial e até mesmo enganadora, na medida em que os erros cometidos sobre determinado contexto não necessariamente indicam um nível mais básico de aquisição, podendo ser resultado de generalizações indevidas que fazem parte do curso do desenvolvimento.

É imprescindível, portanto, que o professor compreenda melhor como ocorre a aquisição de aspectos ortográficos e os níveis de conhecimento que a criança constrói acerca da língua escrita. Isto pode auxiliá-lo na elaboração de situações didáticas que promovam a aquisição da ortografia pela criança, tornando a sala de aula um espaço de discussão e elaboração deste conhecimento.

\section{Referências}

Carraher, T. N. (1985). Explorações sobre o desenvolvimento da competência em ortografia em português. Psicologia: Teoria e Pesquisa, 1(3), 269-285.

Cardoso-Martins, C. (Org.). (1995). Consciência fonológica e alfabetização (pp. 69-100). Petrópolis: Vozes.

Gombert, J. E. (1992). Metalinguistic development. London: Harvester-Wheatsheaf.

Goswami, U. \& Bryant, P. (1990). Phonological skills and learning to read. London: Erlbaum.

Leal, T. F. \& Roazzi, A. (2000). A criança pensa... e aprende ortografia. Em A. G. de Morais (Org.), O aprendizado da ortografia (pp. 99-120). Belo Horizonte: Autêntica.

Monteiro, A. M. L. (1995). A aquisição das regras ortográficas de contexto na leitura e na escrita. Dissertação de Mestrado. Universidade Federal de Pernambuco, Recife.

Monteiro, A. M. L. (2000). "Sebra - ssono - pessado - asado" O uso do "S" sob a ótica daquele que aprende. Em A. G. de Morais (Org.), O aprendizado da ortografia (pp. 43-60). Belo Horizonte: Autêntica.

Morais, A. G. (1998). Ortografia: Ensinar e aprender. São Paulo: Ática.

Morais, A. G. (1999). Ortografia: Este peculiar objeto de conhecimento. Em A. G. de Morais (Org.), O aprendizado da ortografia (pp. 7-19). Belo Horizonte: Autêntica.

Nunes, T. (1992). Leitura e escrita: Processos e desenvolvimento. Em E. S. de Alencar (Org.), Novas contribuições da psicologia aos processos de ensino e aprendizagem (pp. 13-50). São Paulo: Cortez.

Nunes, T., Bryant, P. \& Bindman, M. (1997). Morphological spelling strategies: Developmental stages and processes. Developmental Psychology, 33(4), 637-649.

Pinheiro, A. M. V. (1996). Contagem de freqüência de ocorrência de palavras expostas a crianças na faixa pré-escolar e séries iniciais do $1^{\circ}$ grau. [Software]. São Paulo: Associação Brasileira de Dislexia.

Rego, L. L. B. (1995). Diferenças individuais na aprendizagem inicial da leitura: Papel desempenhado por fatores metalingüísticos. Psicologia: Teoria e Pesquisa, 11(1), 51-60.

Rego, L. L. B. \& Buarque, L. L. (1997). Consciência sintática, consciência fonológica e aquisição de regras ortográficas. Psicologia: Reflexão e Crítica, 10(2), 199-217.

Rego, L. L. B. \& Buarque, L. L. (1999). Algumas fontes de dificuldade na aprendizagem de regras ortográficas. Em A. G. de Morais (Org.), O aprendizado da ortografia (pp. 21-41). Belo Horizonte: Autêntica.

Sá, J. L. S. N. (1999). A relação entre consciência morfossintática e escrita ortográfica. Dissertação de Mestrado. Universidade Federal do Rio de Janeiro, Rio de Janeiro.

Recebido em 07.06.2004

Primeira decisão editorial em 28.01.2005

Versão final em 30.03.2005

Aceito em 08.04.2005 